\title{
A Multilevel Model Examining the Relationships Between Workplace Spirituality, Ethical Climate and Outcomes: A Social Cognitive Theory Perspective
}

\author{
Lilian Otaye-Ebede $^{1}$ (D) Samah Shaffakat ${ }^{2} \cdot$ Scott Foster $^{1}$
}

Received: 27 January 2018 / Accepted: 22 February 2019 / Published online: 5 March 2019

(c) The Author(s) 2019

\begin{abstract}
The role and influence of workplace spirituality on individual and organisational outcomes continue to draw attention among management scholars. Despite this increased attention, extant literature has yielded limited insights particularly into the impact and influence processes of workplace spirituality on performance outcomes at both the individual and unit levels of analysis. Addressing this gap in research, we proposed and tested a multilevel model, underpinned by social cognitive theory, that examines the processes linking perceptions of workplace spirituality and performance outcomes at the individual and organisational level of analysis. Data were obtained from 51 branches of a retail organisation in the United Kingdom. Results from structural equation modelling analysis revealed three salient findings. First, workplace spirituality was positively related to ethical climate, prosocial motivation, and moral judgment. Second, ethical climate partially mediated the relationship between workplace spirituality and prosocial motivation and moral judgment, respectively. Third, aggregated ethical climate significantly relates to branch-level helping behaviour and service performance.
\end{abstract}

Keywords Workplace spirituality $\cdot$ Ethical climate $\cdot$ Moral judgment $\cdot$ Prosocial motivation $\cdot$ Helping behaviour $\cdot$ Service performance

\section{Introduction}

The dynamic and unstable business environment caused by the current tumultuous societal and political landscape, coupled with the increasingly global world of work, has underscored the criticality of promoting an organisational culture that fosters employee well-being, engagement and performance (e.g. Petchsawang and Mclean 2017). One such cultural practice that has received increased research attention is workplace spirituality defined as 'a framework of organisational values evidenced in the culture that promotes

Lilian Otaye-Ebede

1.e.otaye@1jmu.ac.uk

Samah Shaffakat

samah.shaffakat@insead.edu

Scott Foster

s.foster@ljmu.ac.uk

1 Liverpool Business School, Liverpool L3 5UG, UK

2 Department of Organizational Behavior, INSEAD Asia Campus, Singapore 138676, Singapore employees' experience of transcendence through the work process, facilitating their sense of being connected to others in a way that provides feelings of completeness and joy (Giacalone and Jurkiewicz 2003, p. 13).

The surge in interest in workplace spirituality has resulted in the development of numerous theories and scholarly work into its outcomes (e.g. Kolodinsky et al. 2008; Milliman et al. 2003; Pawar 2009). Predominantly, research has focused on the positive impact of workplace spirituality on employee work attitudes such as increased job satisfaction (e.g. Lee et al. 2014), employee engagement (e.g. Roof 2015), organisational commitment, reduced intention to quit (e.g. Gatling et al. 2016) and decline in deviant behaviours (e.g. Ahmad and Omar 2014). Few studies have examined its impact on group-level outcomes such as organisational productivity (Fry and Matherly 2006a), and work unit performance (Duchon and Plowman 2005). Alongside these scholarly articles noting the positive effect of workplace spirituality on outcomes, there is also a growing body of critical scholars arguing the potential harmful effect of organisations using spirituality as a tool for increasing 
organisational performance (e.g. Houghton et al. 2016; Kamoche and Pinnington 2012).

Despite the scholarly contributions of existing studies, there is still an evident dearth in research on the topic which limits the extension, development and application of the concept (Gatling et al. 2016; Pawar 2014). Scholars have noted these inadequacies in existing research and have suggested future research requirements to enhance our understanding of the topic (cf. Pawar 2014). Below, we outline four research requirements expressed in the existing literature that would help in positioning the present study.

First, although early research noted that "theory conceptualization appears to be stronger than empirical evidence" in spirituality literature? (de Klerk 2005, p. 65), to date, this limitation still exists, hence the requirement for greater emphasis on empirical studies. Indeed, Giacalone (2012) highlighted the increasing need for more evidence-based empirical research into the impact of spirituality on organisational life.

Second, Sheep (2006, p. 371) notes that workplace spirituality's "inclusion in established research streams is long overdue" and also suggests that future research should empirically test the relationships among ethical work climate combinations and ethical dilemmas of workplace spirituality as an important step in theory building. His suggestion is similar to Parboteeah and Cullen (2003), and more recently Lee et al. (2014) who proposed relationships between workplace spirituality and ethical work climate. Despite these suggestions and the theoretically established importance of antecedents to organisational ethical climate (e.g. Wang and Hsieh 2013; Demirtas and Akdogan 2015), no research to our knowledge has examined the impact of workplace spirituality in creating an ethical climate which could in turn influence individual- and organisationallevel outcomes. Research conducted by Vitell et al. (2016) examined spirituality and ethics. Focusing on consumer spirituality, their results showed that the more spiritual an individual consumer is, the more likely that consumer is to be ethically predisposed. Indeed, spiritual experiences play a vital role in influencing the ethicality of decisions (Zsolnai 2011) as it helps individuals transcend narrow self-conceptions and exercise genuine empathy with others (e.g. moral judgement), hence taking an all-compassing perspective. Workplace spirituality, in particular, promotes a culture where individuals are encouraged to have an inner experience of interconnectedness with all living things (cf. Bouckaert and Zsolnai 2012). By so doing, it helps employees distance themselves from the pressures and routines of work, restores intrinsic motivation (such as prosocial motivation) and consequently employees develop innovative ethical ideas and practices (Bouckaert and Zsolnai 2012). The overarching argument (examined in this paper) therefore is that workplace spirituality is an essential tool needed for an organisation to build an ethical climate; encourages employees to engage in moral self-regulation, and promotes a culture of prosocial motivation.

Third, the equivocality of the documented influence of workplace spirituality on outcomes noted above calls for more research that explicates the intermediate linkages in this relationship. For example, research has proposed workplace spirituality values, ethical climate (Lee et al. 2014); and in few instances examined job satisfaction (Ahmad and Omar 2014) and supervisors organisational commitment (Gatling et al. 2016) as underlying mechanisms of the influence of workplace spirituality-outcome relationship. These studies however, are few, and have yielded only limited insights into the influence of workplace spirituality on individual- and organisational-level outcomes. Consequently, there is a need for multilevel research to examine simultaneously the impact and influence processes of workplace spirituality at both the individual and organisational levels. This is particularly important if we are to more accurately understand how and why individual and organisational influences shape the performance effects of workplace spirituality. Thereby providing organisations and their managers with actionable knowledge about the importance of creating a culture where spirituality at work thrives, and informing them on how best to create and sustain that culture for continuous competitive advantage.

Finally, empirical evidence suggests that in a spiritual workplace 'wellness' policies lead to enhanced employee performance, in the United Kingdom (UK); however, the employees' basic spiritual well-being is deemed not to be a workplace issue (Shinde and Fleck 2015). In addition, despite the importance of religious beliefs to people in the UK, employers and employees traditionally regard the workplace as off-limits for any demonstration of faith (Ali 2010). However, the separation of spirituality and business is becoming blurred and as such, the workplace is being transformed into an environment where expressions of spirituality and practices are now regarded as more commonplace (Abuznaid 2006). This approach to spirituality in the workplace appears to be a matter of acceptance where the majority of organisations are beginning to recognise employees' basic spiritual well-being (Mitroff 2003; Stokes 2011). In spite of this progress, tolerating spirituality in the workplace is found to be an act of benevolence by some employers rather than a plain legal structure (Morgan 2005). It is therefore imperative that more research into spirituality is conducted within the UK in order to highlight its potential importance in improving performance.

Accordingly, and grounded in social cognitive theory (Bandura 1986; Wood and Bandura 1989), in this study using a multilevel model, we examine the impact of workplace spirituality on ethical climate and its effect on the individual-level outcomes of prosocial motivation and moral 
judgment. We also posit that ethical climate will mediate the relationship between workplace spirituality and the individual-level outcomes, and that aggregated ethical climate will influence organisational outcomes of service performance and helping behaviour.

By pursuing these objectives, our study contributes to the literature in four significant ways. First, it contributes to the nascent study of spirituality by identifying workplace spirituality as a central antecedent to creating an ethical climate (c.f. Bouckaert 2015). Business ethics scholars have called for more research on factors that could lead to ethical climate. Some suggestions by scholars include ethical leadership behaviours (Demirtas and Akdogan 2015); informal control methods (Goebel and Weißenberger 2017); human resource systems (Manroop et al. 2014) and so on. Despite these studies, we still know very little about how ethical climates are built (cf. Manroop et al. 2014) and the potential of a firm's workplace spirituality in facilitating the development of enhanced ethical climate perceptions.

Second, calls for the development of empirical studies focusing on workplace spirituality continue to abound (e.g. Afsar and Badir 2017; Geigle 2012). Despite these calls, and as noted earlier, few studies exist which have tested the effects of workplace spirituality on behaviours and even less studies have looked at organisational-level outcomes. More focus has been on the effects of spirituality on employee attitudes (e.g. Lee et al. 2014; Shinde and Fleck 2015; Karakas and Sarigollu 2017). Among those that exist (e.g. Afsar and Badir 2017; Roof 2015; Ahmad and Omar 2014), none have explored prosocial motivation and moral judgment as key outcomes, particularly when workplace spirituality aids the creation of a collective ethical climate. We therefore add to the limited research examining behavioural effects of workplace spirituality.

Third, of the studies that exist, to our knowledge, none has tested a multilevel model of the effects of spirituality on outcomes, particularly organisational-level outcomes. Despite the fact that workplace spirituality is typically considered a unit/organisational-level construct (Ashmos and Duchon 2000), the pathways through which it influences performance have usually been examined as the system/ individual level (e.g. Gatling et al. 2016; Roof 2015). Consequently, we do not yet know whether these system-level pathways can also account for the influence of workplace spirituality on unit-level performance in a service context. Our study therefore fills this gap by examining a multilevel model to understand the relationship between workplace spirituality and outcomes. By adopting a multilevel perspective, our study explicitly recognises that individual and organisational characteristics combine to influence individual and organisational outcomes (Kozlowski and Klein 2000; Aryee et al. 2012), hence, the integrated nature of organisations.
Finally, the majority of empirical studies on workplace spirituality have been conducted in other countries particularly in the USA (see review by Geigle 2012) where spirituality is considered a very important factor in organisational life. Fewer studies exist examining workplace spirituality within Europe, particularly in the UK. It is therefore important to examine these factors within a UK context in order to extend knowledge.

\section{Theoretical Framework and Hypotheses Development}

\section{Social Cognitive Theory}

Social cognitive theory (SCT) originates from the health sciences and describes a human agency model in which individuals proactively self-reflect, self-regulate and self-organise (Bandura 1989). According to Martin et al. (2014), "SCT estimates the ability of an individual to engage in a targeted behaviour, based on internal and external parameters and their interrelationships" (p. 2). Triadic Reciprocity (which represents the co-interaction of personal, environmental and behavioural factors) is core to this theory (Bandura 1986) and acts as regulators and influencers of human behaviour. SCT proposes that morality and other psychosocial factors (such as working conditions, climate, etc.) explain how moral reasoning governs moral conduct (Wood and Bandura 1989). Thus, "social cognitive theory adopts an interactionist perspective to moral phenomena" and presents a framework in which "personal factors, such as moral thought and affective self-reactions, moral conduct and environmental factors all operate as interacting determinants that influence each other in determining outcomes" (Bandura 1986, p. 2).

More specific, SCT suggests that there are variables (internal or external inputs to the system) which act as stimuli to promote (or relegate) behaviour (Martin et al. 2014, p. 2 ). These variables include, but are not limited to skills training, observed behaviour, perceived social support and verbal persuasion, perceived barriers and obstacles, interpersonal states, environmental context, internal and external cues to action. Based on SCT, external cues (e.g. workplace spirituality) and internal cues (e.g. individual spirituality) could act as influencers of employee behaviours such as engaging in prosocial motivation and making judgements which are considered moral. Similarly, the environmental context, such as having a climate that supports ethical behaviour, is likely to influence employees' behaviours resulting in the predisposition to behave in an ethical way (e.g. making moral judgments). Accordingly, and based on SCT, Wood and Bandura (1989) propose that an individual's beliefs (such as their spirituality) and motives form the basis for value judgments (e.g. perception of ethical climate) and morality 
and that their resulting moral conduct (e.g. moral judgment and prosocial motivation) reflects both personal factors as well as the environment.

Underpinned by SCT, we argue that employees within an organisation are influenced by internal and external cues, which prompt them to take ethical actions that are beneficial to the organisation. Based on Bandura (1986), individuals continually regulate their behaviours by self-assessing their own standard of conduct in comparison with environmental circumstances, which encompasses ethical climate (Domino et al. 2009). We also posit that these cues influence the environmental context in which the behaviour occurs. Hence, when an employee perceives or observes the behaviours of fellow colleagues as ethical, it results in their perception of the organisation supporting a general ethical climate which then triggers resultant ethical behaviours such as prosocial motivation, moral judgments, helping behaviours and service performance (see Fig. 1 for Theoretical Model).

\section{Hypotheses Development}

According to Ashmos and Duchon (2000), workplace spirituality helps people to realise they have an inner and outer life, communicate meaning and purpose in work as well as provide a sense of community thereby moving beyond one's economic self-interests. These three dimensions: inner life, meaningful work, and community highlighted by Ashmos and Duchon (2000) are seen as the sine qua non of workplace spirituality. Parboteeah and Cullen (2003) view workplace spirituality as involving more than mere fulfilling of organisational tasks to viewing work as feeding employees' souls. Ethical climate on the other hand has been defined as "prevailing perceptions of typical organisational practices and procedures that have ethical content" (Victor and Cullen 1988, p. 101). According to Schwepker and Hartline (2005), ethical climate is the combined perceptions of an organisations ethical values and behaviours as practiced by

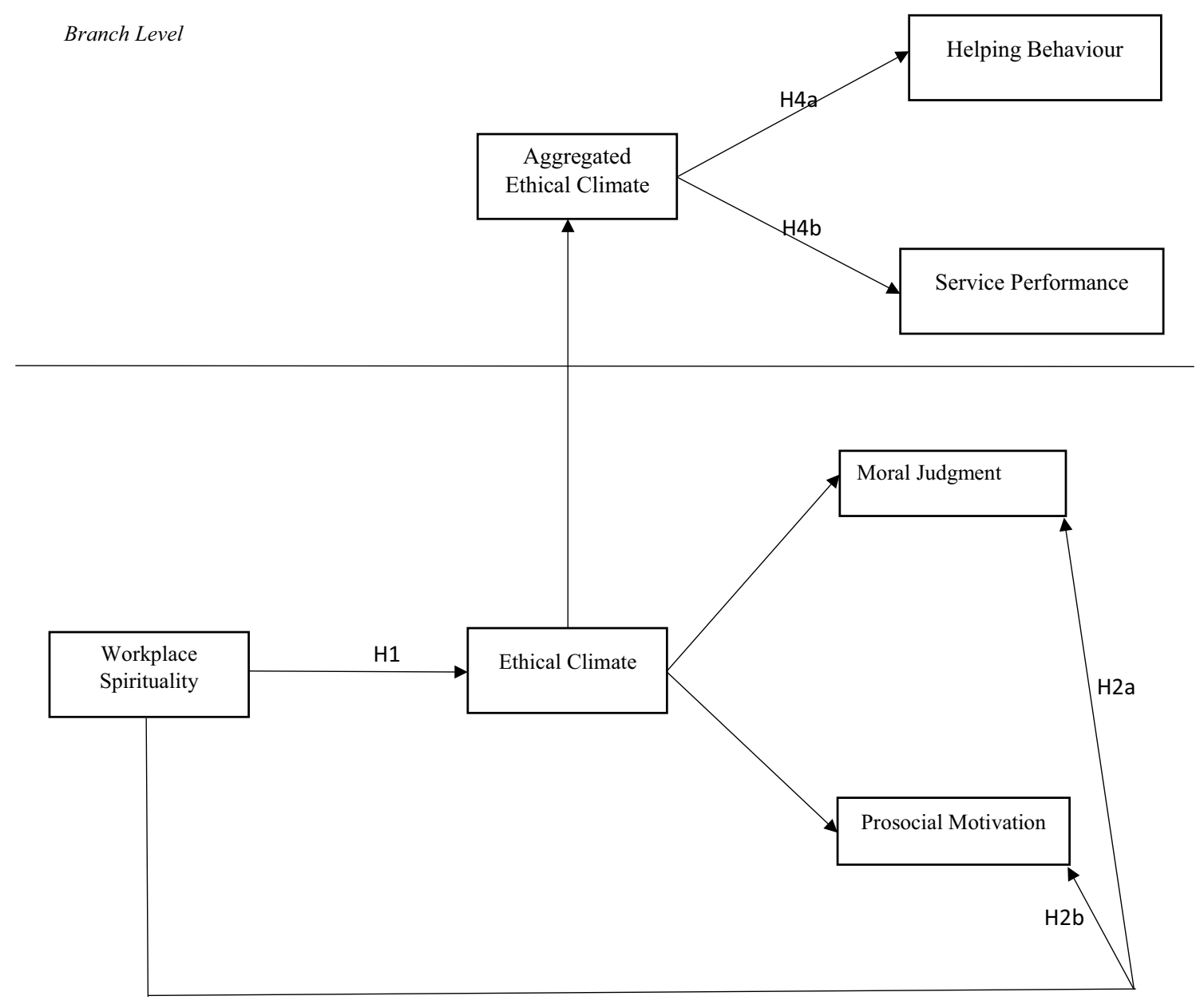

Individual Level

Fig. 1 Proposed theoretical model. H3a posits the mediating role of ethical climate in the relationships between workplace spirituality and moral judgement. H3b posits the mediating role of ethical climate in the relationships between workplace spirituality and prosocial motivation 
the employees and can be majorly influenced by a firm's 'written code of ethics'. These code of ethics encompass a formal, management-initiated control that sets standards of expectations regarding both preferred and problematic behaviours (Weaver 1993).

Workplace spirituality expressed through spiritual codes can have a positive effect on ethical decision-making and the overall ethical climate within an organisation. Spiritual codes, according to Parboteeah and Cullen (2003), can offer the necessary standards for organisations "to follow a morality that demands more than following the minimal standards of acceptability of conventional business practices" (Jackson 1999, p. 61). In other words, spirituality can help employees handle the challenges of the current work environment and produce a work climate conducive to ethical conduct where individuals sincerely care for the well-being of everyone (Wimbush and Shepard 1994). The link between spirituality and ethics has been highlighted in the literature (Furnham 1995; Gunther 2001; Jackson 1999; McKee 2003) with some authors arguing spirituality to be a key component of ethical behaviour (Gull and Doh 2004; Furnham 1996).

McGhee and Grant (2008) see Aristotelian virtue playing a mediating role in the link between spirituality and ethics. They argue that the dimensions of spirituality e.g. the inner life, sense of purpose and feeling part of a community represent a regulative ideal (McGhee and Grant 2008) defined as the normative disposition which guides an individual's conduct and adjusts his or her motivation (Oakley and Cocking 2001). Spiritual individuals follow their regulative ideal focusing more on others' welfare and acting morally well. Overall, spirituality as a personal principle shapes individuals' behaviour when faced with ethical issues by examining the nature of their work as it relates to their personal morality (Giacalone and Jurkiewicz 2003). Such individuals through social interactions, which is a key internal environmental consideration (Ferrell and Weaver 1978), can influence fellow employees' ethical behaviour thereby creating a shared perception of what is ethically right. In other words, the ethical conduct of individuals will collectively produce an ethical climate (Ashforth and Anand 2003; Carlson and Kacmar 1997). We therefore hypothesise:

Hypothesis 1 Workplace spirituality is positively related to ethical climate.

Workplace spirituality helps people to gain greater insights into the ethical problems they face on a daily basis (Gull and Doh 2004). The regulative ideal or the internalised view of spirituality guides the way spiritual individuals act. It produces a web of specific moral values that represent a tendency to be and act in ways that enable a spiritual individual to strive for moral excellence (McGhee and Grant 2008). Moral judgment (i.e. decision as to whether something is ethical or not) stems from these moral values rooted in ethical philosophies which explain how individuals form the standards [the regulative ideal] to decide what is morally right and wrong (Dubinsky and Loken 1989; Jones 1991; Schwepker 1999). The regulative ideal governs the moral choices spiritual individuals face in the workplace-moral dilemmas that require attention and immediate decisions (McGhee and Grant 2008). In other words, judgements, motivations and behaviours which conform with the regulative ideal are employed/exercised and the ones that conflict are discarded (McGhee and Grant 2008). We therefore hypothesize:

Hypothesis 2a Workplace spirituality is positively related to moral judgement.

A key dimension of workplace spirituality is a sense of being connected to others i.e. the sense of community (Ashmos and Duchon 2000). This dimension operates at the group level and relates to the interpersonal relationships at work where people see some type of a connection between one's inner self and those of others (Maynard 1992; Miller 1992; Milliman et al. 2003). This sense of connectedness can increase feelings of empathic concern for the welfare of others which may motivate individuals to engage in behaviours that benefit others (Einolf 2013). This is also supported by research which shows that spiritual individuals tend to have greater compassion towards others (Sprecher and Fehr 2005), behave more altruistically and have higher empathy (Saroglou et al. 2005). The tendency to care for other people's interests is referred to as prosocial motivation and is viewed in terms of prosocial values or attaching significance to maintaining and facilitating well-being of others (Schwartz and Bardi 2001). We therefore hypothesize:

Hypothesis $\mathbf{2 b}$ Workplace spirituality is positively related to prosocial motivation.

As argued above, spiritual individuals follow their regulative ideal which activates their moral imagination and shapes their moral judgment (or behaving in ways that align with their internal moral standards) (Gull and Doh 2004; McGhee and Grant 2008). They are driven by the sense of meaning and purpose, seeing work not just as job but rather a calling. This prompts them to promote ethical conduct at individual and organisational levels (Johnson 2009) thereby creating an ethical climate. Such an atmosphere is essential to the individuals moral development besides the personal influences (Victor and Cullen 1988). It impacts which problems are considered ethical, how they are resolved and the attributes of their resolution (Victor and Cullen 1988). According to Kohlberg, an organisation's "socio-moral atmosphere" is critical to the moral judgement and action of its members. 
For example, in discussing My Lai, Kohlberg (1984, p. 263) argued, "The moral choice made by each individual soldier who pulled the trigger was embedded in the larger institutional context of the army and its decision-making procedures". Victor and Cullen (1988) see the concept of moral atmosphere analogous to an ethical climate in that it reflects the existing norms of the group rather than the individual characteristics. Business ethical decision-making models also highlight the role of "organisational factors" on individual moral or ethical decision-making (Barnett and Vaicys 2000). Trevino (1986) argues that individuals usually look outside for assistance with the ethical issues, as such organisational factors can influence the relationship between mental processing and behaviour through organisational rules, reinforcements and management's influence. Given our arguments above, we believe ethical climate represents a mechanism which enables spiritual individuals to regulate their moral judgments. We therefore hypothesize:

Hypothesis 3a Ethical climate partially mediates the relationship between workplace spirituality and moral judgment.

Spiritual individuals and workplaces aim to serve meaningful goals (Johnson 2009). This prompts them to place high importance on ethical conduct (Johnson 2009). With ethics as a top priority, each individual considers the wellbeing of others in the workplace (Parboteeah and Kapp 2008). Group process characteristics which characterise an ethical climate such as cooperation, personal attraction among members and positive feelings about a task (Wech et al. 1998) may contribute in creating the sense of community. Moreover, an ethical climate where people care for each other may produce more cohesive groups and an even stronger sense of community (Parboteeah and Cullen 2003). Such an ethical climate creates a caring environment where members are sensitive and motivated to help and support each other (Parboteeah and Cullen 2003). Given our arguments above, we see ethical climate as a mechanism which motivates spiritual individuals to care for the well-being of others. We therefore hypothesize.

Hypothesis 3b Ethical climate partially mediates the relationship between workplace spirituality and prosocial motivation.

Helping behaviour in organisations refers to "voluntarily helping others with, or preventing the occurrence of, work- related problems" (Podsakoff et al. 2000, p. 516). It is seen as an important form of citizenship behaviour and includes acts like altruism, peace-making, cheerleading, courtesy and other cooperative, considerate and helpful gestures (Podsakoff et al. 1997, 2000; Van Scotter and Motowidlo 1996). Since citizenship behaviour (i.e. helping behaviour) communicates dynamics between members of an organisation, it should be investigated at the collective level (Shin and Choi 2010). In the current study, collective helping behaviour is conceptualised as the degree to which employees of an organisation together engage in helping behaviour to establish shared norms and expectations (cf. Shin 2012; Nielsen et al. 2012). Such behaviours can be impacted by organisational factors such as climate, culture, leadership and so on (Somech and Drach-Zahavy 2004). For example, research has linked ethical climate to extrarole behaviours (Leung 2008) which can be explained through social exchange theory (Shin 2012). According to this theory, employees are likely to reciprocate in positive and prosocial ways, if they perceive that being part of the organisation contributes to them in a positive and beneficial way (Organ 1988). Therefore, in organisations with a strong ethical climate, employees are likely to engage in prosocial behaviours in exchange for being treated ethically and fairly by their organisation (Leung 2008). Given the arguments above, it is generally expected that an ethical climate has a positive relationship with collective helping behaviour.

Hypothesis 4a Aggregated ethical climate positively relates to branch-level collective employee helping behaviour.

Although ethical climate is a concept at a macro level, its perceptions have consequences for individuals at the micro level (Wyld and Jones 1997). The effects of ethical climate on the performance of individuals have received a lot of attention in the literature (e.g., Schwepker 2001; Valentine and Barnett 2003; Weeks et al. 2004). Individual employees' performances aggregate to produce organisational performance (Bakotić 2016). If the organisation adopts the "do the right thing" philosophy and creates an ethical climate, it should be mirrored in its policies and procedures that align with doing 'what's right' for the internal and external customers (Weeks et al. 2004). An organisation that champions an ethical climate might give high importance to customer service, put in place performance measurement systems that assess and reward high levels of customer satisfaction and hire employees who establish better customer relations through high-quality service (Wimbush and Shepard 1994; Weeks et al. 2004). Research by Weeks and Nantel (1992) links a well-communicated code of ethics to sales force behaviour-sales force working in such an environment can be described to have relatively high job performance. Likewise, Hunt et al. (1989) see ethical values (through commitment) as critical to success. We therefore argue: 
Hypothesis 4b Aggregated ethical climate positively relates to branch-level collective employee service performance.

\section{Method}

\section{Participants and Procedures}

The theoretical framework of this study was tested by collecting data from the managers and employees of a large multi-million-pound retail chain organisation in the UK, consisting of 51 stores nationally and 676 employees. For the purpose of this study, survey information was obtained from all employees, with Sales and General Managers survey data collected separately. In the first instance, Sales Managers and General Managers were invited to rate items of workplace spirituality, the overall service performance and helping behaviour of front-line employees and to report the market performance of their stores. Secondly, the remaining employees were asked to assess their perceptions of workplace spirituality and ethical climate and to rate their prosocial motivations and moral judgments. The questionnaires were sent out through the internal email (electronically) to the General Managers and Sales Managers in individual branches, who printed them off, completed theirs and then distributed the employees' surveys to their respective staff within the branches. To retain anonymity and avoid social desirability, the staff were allowed to complete the survey in their own time and were provided with sealed envelopes in which to return the survey.

To address the possibility of common method variance bias, we followed remedial procedures suggested by Podsakoff et al. (2003). First, the questionnaire as a whole included different response formats: Likert scales with different endpoints, open-ended questions, and reversely scored items. Second, all the relevant concepts in each question were explicitly specified, with examples when needed. Third, to avoid social desirability in answering, participants were guaranteed response anonymity. Finally, as proposed by Frese and Zapf (1988) and applied in Huhtala et al. (2015) research, when using multilevel modelling, the individual results are aggregated at the between level, which helps to minimise the problem of common method variance.

Of the 676 employees, we received a total of 366 surveys from both managers and employees, representing a $54 \%$ response rate. After excluding incomplete surveys, we had 62 manager surveys and 304 employee surveys from 51 stores. Of the 304 employees, $41 \%$ (124) were female, $44.1 \%$ (178) were between the ages of 25-42 years, and reported an average organisational tenure of 3.58 years (s.d. =1.49). In terms of educational attainment, $30.3 \%$ (92) had received at least an undergraduate, GCE A Levels or a first degree. With regard to managers, $19.4 \%$ (12) were female, $64.5 \%$ (40) were between the ages of 34 and 51 years, and reported an average organisational tenure of 4.51 years (s.d. $=1.24)$. In terms of educational attainment, $46.7 \%$ (29) had received at least an undergraduate, GCE A Levels or a first degree.

\section{Measures}

\section{Workplace Spirituality}

We measured workplace spirituality using two of the factors developed by Ashmos and Duchon (2000) and adapted by Milliman et al. (2003). The two factors selected for this study measure workplace spirituality as a unit-level construct and have previously demonstrated satisfactory levels of reliability and validity in other research (e.g. Madden et al. 2015). As described in Ashmos and Duchon (2000), Factor 1 relies on items that describe 'informants' sense of their work community (i.e. the extent to which the work unit is encouraging and caring), while factor 2 describes the extent to which informants identify with the unit's values, goals and mission. These two factors capture notions of community and meaningful work (Ashmos and Duchon 2000) Sample items include, "in this organisation, working cooperatively with others is valued" (Sense of community; $\alpha=0.86$ ); "the organisation I work for cares about whether my spirit is energised by my work" (Alignment to organisational values; $\alpha=0.85$ ). The measure was based on a 7 -point likert-type scale ranging from $1=$ strongly disagree to $7=$ strongly agree. The overall alpha reliability in this study was 0.92 .

\section{Employee Perception of Ethical Climate}

We measured employee ethical climate perceptions with an adapted version of a 3-item scale developed by Mayer et al. (2013), and used by Hansen et al. (2016). Similar to Hansen et al. (2016), we chose this measure because it required respondents to measure their perceptions regarding the ethical climate perceptions of the employees around them, thus, reducing the possibility of socially desirable responses. A sample item includes, "whether employees support me in following my company's ethical standards". The scale ranged from $1=$ strongly disagree to $5=$ strongly agree, and had a Cronbach alpha of 0.76 .

\section{Prosocial Motivation}

We assessed prosocial motivation with a five-item scale used by Grant and Sumanth (2009), which they adapted 
from measures of prosocial motivation (Grant 2008a) and goal orientation at work (Vande Walle (1997). Given that those who benefited from their work were customers, the term 'others' in the scale was used to refer to customers. Items were measured on a 5-point Likert-type scale ranging from $1=$ strongly disagree to $5=$ strongly agree. A sample item is "I get energized by working on tasks that have the potential to benefit others". The alpha reliability in this study was 0.87 .

\section{Moral Judgment}

We measured moral judgment by using the business situation scenario that was adapted from hypothetical ethical dilemmas developed by Frank (2004). This has been applied to undergraduate business students by Brown et al. (2010) and Wang and Calvano (2015) and fit this study as our focus was on examining how employees made moral judgments in a business environment rather than within their personal lives. The business-related dilemma was whether a business owner should inform his or her supplier (a mail-order company) of an error on the bill and ask for the correct amount, which would be higher than the incorrect bill. The scenario asked the respondent to indicate a percentage of how likely they would be to respond in a particular way with answers ranging from 0 to $100 \%$ of likelihood. Higher percentages indicate a greater propensity to be ethical in decision-making.

\section{Aggregated Ethical Climate}

To assess the overall perception of ethical climate for the retail company as a whole, we averaged across branches ratings of the individuals to form branch-level ethical climate. This approach is consistent with prior studies on service performance which have average individual-level service performance to achieve branch-level performance (e.g. Liao and Chuang 2004; Aryee et al. 2012). We also computed intraclass correlation or ICC(1) and reliability of group mean or ICC(2) (Kozlowski and Klein 2000). The ICC(1) was 0.73, and the ICC2 was $0.74, F(303,608)=4.13, p<0.001$, providing support for aggregating to the branch level.

\section{Service Performance}

Service performance was assessed with seven items adapted from Liao and Chuang (2004), which was originally developed by Borucki and Burke (1999). Similar to Chuang and Liao's (2010) study, items were reworded for managers to rate the service performance of their stores as a whole $(1=$ strongly disagree to $7=$ strongly agree $)$. An example item is that "our employees ask good questions and listen to find out what a customer wants". The alpha reliability in this study was 0.65 .

\section{Helping Behaviour}

Helping behaviour was assessed with a seven-item helping subscale of citizenship behaviour developed by Podsakoff et al. (1997). Similar to Chuang and Liao's (2010) study, items were reworded for managers to rate the store employees' overall helping behaviour $(1=$ strongly disagree to $7=$ strongly agree). A sample question is "our employees willingly give of their time to help co-workers who have work-related problems". The alpha reliability in this study was 0.85 .

Because service performance and helping behaviour were rated by managers across different stores, we calculated average mean deviation (AD) index to determine the level of agreement among manager ratings (Chuang and Liao 2010; Burke and Dunlap 2002; Burke et al. 1999). According to Burke and Dunlap (2002), the AD index "involves determining the extent to which each item rating differs from the mean (or median) item rating, summing the absolute values of these deviations (ignoring plus or minus signs), and dividing the sum by the number of deviations" (p. 160). Similar to Chuang and Liao (2010) and as suggested by Burke and Dunlap (2002), we adopted an upper-limit cutoff of 0.83 (c/6, where $\mathrm{c}$ indicating the number of response options for a measure item) when a 5-point Likert scale is used, with smaller indices indicating stronger agreement among raters. The AD index for each item of helping behaviour (ranged between 0.70 and 0.71 ), and service performance (ranged between 0.53 and 0.54 ) all showed that the managers at the various stores reached an acceptable level of agreement. We also computed intraclass correlation or ICC(1) and reliability of group mean or ICC(2) (Kozlowski and Klein 2000). ICC(1) values were significant for the two variables, with the values of 0.78 for helping behaviour, and 0.44 for service performance. In addition, $\operatorname{ICC}(2)$ values for helping behaviour and service performance, were 0.85 and 0.65 , respectively.

Control Variables. We controlled for respondents' age, gender and ethnicity because previous research has shown them to be related to spirituality and various attitudes and behaviours (e.g. Roof 2015; Vitell et al. 2016). Gender was coded $1=$ male and $2=$ female; age was coded $1=16-24$, $2=25-33,3=34-42,4=43-51$ and $5=52+$. Ethnicity was coded $1=$ Asian, $2=$ White British, $3=$ Indian, $4=$ Pakistani, $5=$ Bangladeshi, $6=$ Black Caribbean, $7=$ Black British, $8=$ Black African, $9=$ Chinese, $10=$ Irish, $11=$ Mixed race and $12=$ Other.

\section{Data Analysis}

Our model is multilevel in nature, consisting of variables at both the branch level (i.e. aggregated ethical climate, helping behaviour and service performance) and individual level (i.e. 
workplace spirituality, perception of ethical climate, prosocial motivation and moral judgment). We used structural equation modelling (SEM) to test our Hypotheses (i.e. to examine the directed and mediated relationships proposed in the research model), as recommended by researchers (e.g. Chuang and Liao 2010; James et al. 2006; MacKinnon et al. 2002). This was done using IBM SPSS Amos 23. According to MacKinnon et al. (2002), SEM provides a better balance of Type I error rates and statistical power by simultaneously testing both paths from an independent variable to a mediator and from the mediator to the dependent variable (p. 83).

As recommended by Hair et al. (1998), given the sample size of the respondents at the branch level, we used Maximum likelihood estimation procedure, which is deemed an appropriate method for smaller sample sizes. Similar to other scholars e.g. Chuang and Liao (2010), to increase the ratio of sample size to free parameter, we combined the scale items to create three "composite" indicators for service performance and helping behaviour, respectively, following the procedure by Mathieu and Farr (1991).

To test the hypothesised mediating role of subordinates' perception of ethical climate, we first assessed the following conditions for mediation: (a) The independent variable must be related to the mediator, (b) the mediator must be related to the dependent variable and (c) the independent variable must have no effect on the dependent variable when the mediator is held constant (full mediation) or the effect should become significantly smaller (partial mediation; Kenny et al. 1998). We compared an alternative partially mediated model (adding paths from workplace spirituality to prosocial motivation and moral judgment) with the hypothesized model (fully mediated) to examine the third condition of mediation. To further provide a more rigorous test, we followed Preacher and Hayes' (2008) bootstrapping procedure for assessing and comparing indirect effects. We used AMOS 23.0 (SPSS Inc., 2008) to conduct the simulation and bootstrapping procedures.

To assess model fit in this analysis and throughout this article, we adopted the standards from the literature that reasonable fit is indicated by comparative fit index (CFI) and incremental fit index (IFI) values greater than 0.90 and root-mean-square error of approximation (RMSEA) values less than 0.10 (Diamantopoulos and Siguaw 2000; Hu and Bentler 1995).

\section{Results}

\section{Measurement Issues}

Prior to testing the statistical model, we conducted a series of confirmatory factor analyses (CFA). CFA was used to test the fit of the measurement model i.e. whether each of the measurement items specified loaded significantly onto the latent constructs with which they were associated. Specifically, we conducted CFA to examine whether workplace spirituality (sense of community and organisational values), perception of ethical climate, prosocial motivation and moral judgment, captured distinct constructs at the individual level of analysis. To do this, we first examined a measurement model that included all five measures (i.e. workplace spirituality (sense of community and organisational values), perception of ethical climate, prosocial motivation and moral judgment). We then compared the five-factor measurement model to more parsimonious models that set two of the hypothesized five factors to correlate at 1.0 to keep the basic measurement model structure equivalent, allowing for meaningful Chi-square difference tests.

Results showed that the hypothesized 5-factor measurement model fits the data well, $\chi^{2}(242, N=304)=650.47$, $p<0.001, \mathrm{CFI}=0.90, \mathrm{IFI}=0.90, \mathrm{RMSEA}=0.07$. Relative to the hypothesized model, the fit for an alternative model in which we set the covariance between the perception of ethical climate and prosocial motivation to be equal to 1.0 was worse, $\chi^{2}(243, N=304)=692.77, p<0.001$, $\mathrm{CFI}=0.89, \mathrm{IFI}=0.89$, RMSEA $=0.07$; so was that for a second alternative model, in which we set the covariance between the two workplace spirituality factors (i.e. sense of community and organisational values) to be equal to $1.0, \chi^{2}(243, N=304)=670.63, p<0.001, \mathrm{CFI}=0.89$, $\mathrm{IFI}=0.89, \mathrm{RMSEA}=0.08$. Similarly, the hypothesized five-factor model had a superior fit to a model in which we set the covariance between one aspect of spirituality (i.e. sense of community) and ethical climate to be equal to 1.0 , $\chi^{2}(243, N=304)=699.54, p<0.001, \mathrm{CFI}=0.89, \mathrm{IFI}=0.89$, RMSEA $=0.08$. These results provide support for the discriminant validity of our employee self-rated constructs.

\section{Hypothesis Tests}

Table 1 presents the means, standard deviations, correlations and coefficient alphas $(\alpha)$ among the study variables at the individual level. As shown in Table 1, all hypothesized pairs of relationships were statistically significant.

Hypothesis 1 suggested that individual-level spirituality would be related to ethical climate. As depicted in Fig. 2, we found a strong, positive relationship between the workplace spirituality and perception of ethical climate $(\gamma=0.89$, $p<0.01$ ), thus Hypothesis 1 received support.

Hypothesis 2a suggested that workplace spirituality would be related to moral judgement, and Hypothesis $2 \mathrm{~b}$ posited that workplace spirituality would be related to prosocial motivation. As depicted in Fig. 2, we found a positive relationship between workplace spirituality and moral judgment $(\gamma=0.49, p<0.001)$ as well as a strong, positive 
Table 1 Means, standard deviations, reliabilities and intercorrelations among study variables

\begin{tabular}{|c|c|c|c|c|c|c|c|c|c|c|c|}
\hline & Variables & M & SD & 1 & 2 & 3 & 4 & 5 & 6 & 7 & 8 \\
\hline 1 & Sense of community & 3.07 & 0.89 & $(0.93)$ & & & & & & & \\
\hline 2 & Alignment to organisational values & 3.39 & 0.88 & $0.84 * *$ & $(0.88)$ & & & & & & \\
\hline 3 & Perception of ethical climate & 4.38 & 1.00 & $0.60 * *$ & $0.65 * *$ & $(0.73)$ & & & & & \\
\hline 4 & Prosocial motivation & 3.42 & 0.72 & $0.72 * *$ & $0.73 * *$ & $0.66^{* *}$ & $(0.81)$ & & & & \\
\hline 5 & Moral judgment & 3.41 & 0.80 & $0.50 * *$ & $0.36 * *$ & $0.36^{* *}$ & $0.56^{* *}$ & $(0.81)$ & & & \\
\hline 6 & Age & 2.08 & 1.00 & -0.00 & 0.01 & 0.02 & 0.04 & 0.00 & - & & \\
\hline 7 & Gender & 1.48 & 0.50 & 0.11 & 0.04 & -0.01 & 0.05 & $0.15^{*}$ & -0.11 & - & \\
\hline 8 & Ethnicity & 3.66 & 1.41 & -0.06 & -0.09 & -0.09 & -0.08 & -0.02 & -0.03 & 0.07 & - \\
\hline
\end{tabular}

$N=304$. Coefficient alphas are listed in parentheses along the diagonal

${ }^{*} p<0.05,{ }^{* *} p<0.01$ (2-tailed)

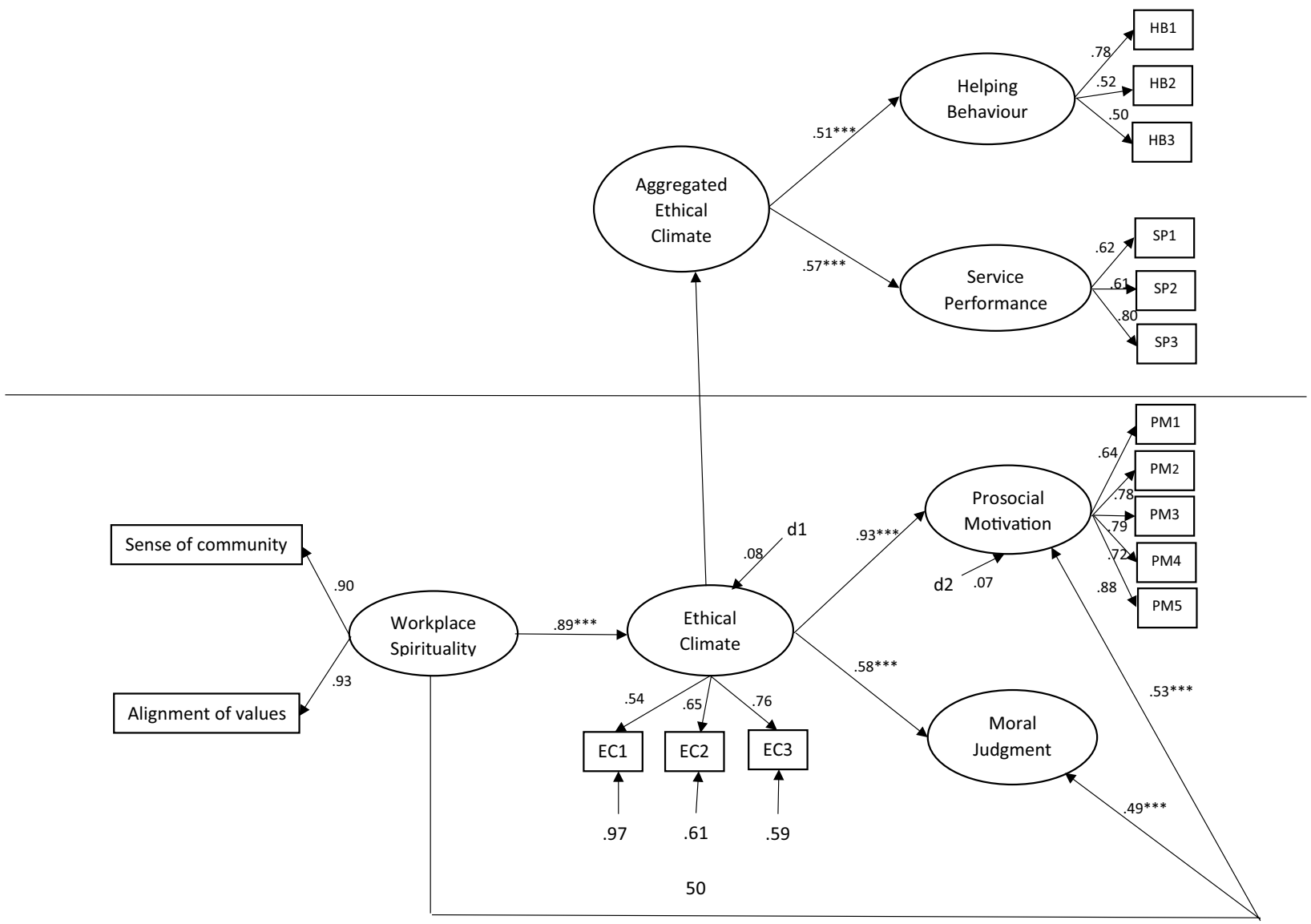

Fig. 2 Results from Structural Model

relationship between workplace spirituality and prosocial motivation $(\gamma=0.53, p<0.001)$, thus supporting Hypotheses $2 \mathrm{a}$ and $2 \mathrm{~b}$.

Hypotheses $4 \mathrm{a}$ and $4 \mathrm{~b}$ posited that aggregated ethical climate would positively influence branch-level helping behaviour and service performance, respectively. Results showed that aggregated ethical climate significantly relates to branch-level helping behaviour $(\gamma=0.51, p<0.001)$ and branch-level service performance $(\gamma=0.57, p<0.001)$, thus supporting Hypotheses $4 \mathrm{a}$ and $4 \mathrm{~b}$.

\section{Mediation Analysis}

Hypotheses $3 \mathrm{a}$ and $3 \mathrm{~b}$ suggested that ethical climate will partially mediate the influence of workplace spirituality 
on moral judgment and prosocial motivation, respectively. As noted earlier, we used SEM to test these hypotheses, controlling for age, gender and ethnicity. SEM was undertaken using AMOS 23 to test the mediation Hypotheses. Following recent best practice (e.g. Wood et al. 2010; Zhao et al. 2010), we conducted two sets of structured equation modelling: a full mediation model (in which direct effects from workplace spirituality to the two dependent variables-prosocial motivation and moral judgement were not included) and a partial mediation model (where direct paths from workplace spirituality to the two dependent variablesprosocial motivation and moral judgement were included). The goodness-of-fit indices for the full mediation model were $\chi^{2}=161.45, \mathrm{df}=63$, RMSEA $=0.072, \mathrm{IFI}=0.95$, $\mathrm{CFI}=0.95$, and for the partial mediation model $\chi^{2}=141.66$, $\mathrm{df}=61, \mathrm{RMSEA}=0.066, \mathrm{IFI}=0.96, \mathrm{CFI}=0.96$. The results showed that the chi-squared for the partial mediation model was significantly smaller $\left(\Delta \chi^{2}=19.79, \Delta \mathrm{df}=2, p<0.001\right)$ than that of the full mediation model. Following James, Mulaik and Brett (2006), the partial mediation model was accepted as the better model because it slightly improved fit over the full mediated model. Additionally, the Akaike Information Criterion (AIC: Akaike 1987) values showed that our hypothesized partially mediated model had a smaller value $(\mathrm{AIC}=229.66)$ than the fully mediated alternative model ( $\mathrm{AIC}=245.45$ ), reinforcing our decision to accept the parsimonious hypothesized model as the best-fitting model. Thus, providing support for Hypotheses $3 \mathrm{a}$ and $3 \mathrm{~b}$. Table 2 shows the direct and indirect effects of the mediation tests.

To further provide a more rigorous test and cross-validate the mediated findings described above, we followed Preacher and Hayes' (2008) bootstrapping procedure for assessing and comparing indirect effects in mediator models. We used AMOS 23 to conduct the simulation and bootstrapping procedures. Results from the bootstrapping analysis suggest that the indirect effect of workplace spirituality on prosocial

Table 2 Structural equation path coefficients

\begin{tabular}{|c|c|c|}
\hline & \multicolumn{2}{|c|}{$\begin{array}{l}\text { Standardised path coef- } \\
\text { ficients }\end{array}$} \\
\hline & $\begin{array}{l}\text { Model 1(full } \\
\text { Mediation) }\end{array}$ & $\begin{array}{l}\text { Model } \\
\text { 2(partial } \\
\text { Mediation) }\end{array}$ \\
\hline $\begin{array}{l}\text { Workplace spirituality-prosocial motiva- } \\
\text { tion }\end{array}$ & & $0.53 * * *$ \\
\hline Workplace spirituality-moral judgment & & $0.49 * * *$ \\
\hline Workplace spirituality-ethical climate & $0.89 * * *$ & $0.79 * * *$ \\
\hline Ethical climate-prosocial motivation & $0.93 * * *$ & $0.41 * * *$ \\
\hline Ethical climate-moral judgment & $0.58 * * *$ & $0.09 \mathrm{~ns}$ \\
\hline
\end{tabular}

$N=304$

${ }^{*} p<0.05, * * p<0.01, * * * p<0.001$ (2-tailed) motivation through ethical climate was positive and significant $(0.32 ; 95 \%$ bias-corrected $\mathrm{CI}=0.11,0.99)$. Furthermore, the indirect effect of workplace spirituality on moral judgement was positive and significant $(0.07$; $95 \%$ biascorrected $\mathrm{CI}=-0.20,0.58$ ). Because zero is not in the $95 \%$ intervals, we conclude that the indirect effects are indeed, significantly different from zero $(p<0.05$, two-tailed).

\section{Discussion}

Grounded in Bandura's (1989) social cognitive theory, we examined the effects of workplace spirituality on ethical climate and its subsequent relationships with the individual-level outcomes of prosocial motivation and moral judgment. The study also aimed to examine the mediating role of ethical climate between workplace spirituality and the individual-level outcomes; and to test how aggregated ethical climate will influence organisational outcomes of service performance and helping behaviour. The findings revealed that when employees perceive that their organisation works towards facilitating an environment that supports and encourages workplace spirituality, as reflected through its values and sense of community, it is more likely to affect their perception of the overall ethical organisational climate (cf. Jurkiewicz and Giacalone 2004). Similarly, this perception creates an environment where the employees are more likely to be motivated to behave in a prosocial manner and to make good moral judgements. These findings are consistent with those of other researchers that have found workplace spirituality to influence ethical climate (e.g. Lee et al. 2014) and employees' behaviours such as increasing organisational citizenship behaviour (Milliman et al. 2003), innovative work behaviours (Afsar and Badir 2017) and reducing deviant behaviours at work (Ahmad and Omar 2014). However, our study differs and goes further to demonstrate not just the direct effect of workplace spirituality on the employee behaviours of prosocial motivation and moral judgment, but that this relationship works through perception of ethical climate to enhance these behaviours. We discuss the implications of these findings in the succeeding sections.

\section{Theoretical Implications}

Our findings advance knowledge of workplace spirituality and ethical climate in three ways. First, our findings provide empirical evidence to show the value of workplace spirituality in organisational life. Particularly, we show how encouraging spirituality within the workplace is a prerequisite for ethical decision-making amongst employees, hence creating a composite ethical climate. Our findings also show that moral judgment and prosocial motivation are driven by a spiritual work climate. Thus, providing support 
for Bouckaert (2015) and Zsolnai's (2015) argument that a spiritual approach to business ethics is badly needed and is one of the few factors that create a sustained ethical climate.

Second, our findings not only revealed the performance implications of workplace spirituality within the UK context, but also showed this relationship to be indirect through ethical climate that emerge at the branch level as aggregated ethical climate. We therefore add to the spirituality research by adopting a multilevel perspective in examining the role of ethical climate in accounting for the performance effects of workplace spirituality. Specifically, the results of the current study suggest that employees' shared perception of the organisational ethical climate is associated with positive organisational outcomes-collective helping behaviour and service performance. Although, previous research has examined the relationship between ethical climate and work outcomes, it has mainly been at the individual level (e.g. Elçi and Alpkan 2009; DeConinck 2010; Mulki et al. 2008). By revealing the organisational-level dynamics among workplace spirituality, ethical climate, collective employee helping behaviour and service performance, the current study adds to the research on workplace spirituality and business ethics at the macro level. It contributes to the literature needed to study different elements of spirituality and ethics in the workplace to prevent unethical behaviour from becoming a norm.

Finally, our study underpinned by social cognitive theory provides strong evidence of the positive effect of workplace spirituality. The equivocal findings noted above called for more empirical evidence on the potential positive outcomes of workplace spirituality, our study's findings provide this evidence. We show that encouraging workplace spirituality could act as an influencer of employee behaviours such that it propels them to engage in prosocial motivation and making judgements which are considered moral. Similarly, the environmental context such as having a climate that supports ethical behaviour is likely to influence employees' behaviours resulting in the predisposition to behave in an ethical way (e.g. making moral judgments).

\section{Practical Implications}

Since workplace spirituality is the potential influencer of ethical climate, organisations should train employees to understand the positives of workplace spirituality. Different ways to impart these values should be researched. For example, spiritual development program should be a part of the training activities in organisations to see how these impacts the workplace outcomes (Dent et al. 2005). Managers should also understand the spiritual needs of the workforce, create a supportive work environment and carefully observe the individual and organisational milestones which are met. Furthermore, it is critical to establish an organisational climate which prioritises collective achievement or citizenship behaviours, rather than self-interest. Such norms increase the connection between an individual's self-concept and work, meaning in work, and feeling part of the community (Badrinarayanan and Madhavaram 2008).

The findings may be of particular interest to managers and organisations interested in encouraging helping behaviour and increasing service performance on the part of their employees. Research shows that the employees develop a positive perception of the workplace when there are clear standards that assist them in determining what is ethical or unethical (Trevino et al. 2001; Valentine and Barnett 2003). High ethical standards increase the efficiency of employees and improve their well-being. Espousing an ethical climate involves being ethical to internal and external customers through high levels of customer service. Managers and supervisors should act as a role model here for employees to emulate. Employees perceiving such a climate show higher levels of performance as they see high-quality work as ethical (Weeks et al. 2004) and feel a sense of caring towards others (Leung 2008).

\section{Limitations and Directions for Future Research}

These findings though significant must be interpreted against a backdrop of limitations, and by discussing them we are simultaneously highlighting some directions for future research. First, the cross-sectional design of our study precludes any inference of causality. Although our study is grounded in social cognitive theory and the relationships we reported are consistent with our predictions and theory, future research with a longitudinal design will be better suited to addressing the directionality and strength of the relationships we examined.

Second, there might be additional factors to consider in managing a service organisation. For example, leaders and leadership style can play a critical role in shaping the employee ethical climate perceptions and encourage affective commitment and reduced turnover intention (Demirtas and Akdogan 2015). Store managers may be influential in communicating information about management policies and practices directed toward customers and reinforcing management practices (Borucki and Burke 1999) directed at increasing workplace spirituality and ethical climate. Given poor leadership, workplace spirituality is less likely to have strong impacts on climate perceptions and employee performance. We therefore encourage future research to examine the role of leadership in the relationship between workplace spirituality and organisational performance.

Third, in this study, we were unable to obtain objective measures of unit performance. We measured unit-level performance by obtaining data on service performance and helping behaviour from supervisors and managers in 
individual branches. This is consistent with other researchers (e.g. Chuang and Liao 2010) and the existence of a large body of literature linking employee service performance and extra-role behaviour with desirable sales and financial performance (e.g., Borucki and Burke 1999; Schneider et al. 2005) can be seen as lending support to link employee behaviours and objective market. Nonetheless, we encourage future research to obtain objective performance data and also to complement data from an internal source with those from external stakeholders, such as customers (Schneider et al. 2005). Finally, as the data in this study were collected from a sample of employees within the retail sector, the generalisation of our findings to other sectors and industries should be taken cautiously. To broaden the applicability of our findings, future research can replicate the study in other industries.

\section{Conclusion}

The current business environment places a premium on understanding the factors that could mitigate ethical misconduct and trigger positive employee responses. We therefore conducted a study examining the role of workplace spirituality in establishing an ethical climate and influencing workplace behaviours and outcomes. Though numerous antecedents of ethical climate have been studied, workplace spirituality may be the direct explanation. Through social interactions, spiritual individuals create a shared perception of what is ethical or unethical which also influences their moral judgment as well as their motivation to help and support each other. Our study further shows that such organisations also experience higher levels of service performance and collective helping behaviour from employees. We hope the findings of this study and the suggested directions for future research will provide actionable knowledge that will enable organisations to more effectively develop and leverage the positive influence of workplace spirituality in creating an ethical climate and increasing performance outcomes among employees.

\section{Compliance with Ethical Standards}

Conflict of interest The authors declare that they have no conflict of interest.

Open Access This article is distributed under the terms of the Creative Commons Attribution 4.0 International License (http://creativeco mmons.org/licenses/by/4.0/), which permits unrestricted use, distribution, and reproduction in any medium, provided you give appropriate credit to the original author(s) and the source, provide a link to the Creative Commons license, and indicate if changes were made.

\section{References}

Abuznaid, S. (2006). Islam and management: What can be learned? Thunderbird International Business Review, 48(1), 77-91.

Afsar, B., \& Badir, Y. (2017). Workplace spirituality, perceived organisational support and innovative work behavior: The mediating effects of person-organisation fit. Journal of Workplace Learning, 29(2), 95-109.

Ahmad, A., \& Omar, Z. (2014). Reducing deviant behavior through workplace spirituality and job satisfaction. Asian Social Science, 10(19), 107-112.

Akaike, H. (1987). Factor analysis and AIC. Psychometrica, 52, $317-332$.

Ali, A. J. (2010). Islamic challenges to HR in modern organisations. Personnel Review, 39(6), 692-711.

Aryee, S., Walumbwa, F. O., Seidu, E. Y. M., \& Otaye, L. E. (2012). Impact of high-performance work systems on individual- and branch-level performance: Test of a multilevel model of intermediate linkages. Journal of Applied Psychology, 97, 287-300.

Ashforth, B. E., \& Anand, V. (2003). The normalization of corruption in organisations. Research in Organisational Behavior, 25, 1-52.

Ashmos, D. P., \& Duchon, D. (2000). Spirituality at work: A conceptualization and measure. Journal of management inquiry, 9(2), $134-145$.

Badrinarayanan, V., \& Madhavaram, S. (2008). Workplace spirituality and the selling organisation: A Conceptual Framework and Research Propositions. Journal of Personal Selling \& Sales Management, 28(4), 421-434.

Bakotić, D. (2016). Relationship between job satisfaction and organisational performance. Economic Research-Ekonomska Istraživanja, 29(1), 118-130.

Bandura, A. (1986). Social foundations of thought and action: A social cognitive theory. Englewood Cliffs: Prentice-Hall.

Bandura, A. (1989). Human agency in social cognitive theory. The American psychologist, 44(9), 1175-1184.

Barnett, T., \& Vaicys, C. (2000). The moderating effect of individuals' perceptions of ethical work climate on ethical judgments and behavioral intentions. Journal of Business Ethics, 27(4), 351-362.

Borucki, C. C., \& Burke, M. J. (1999). An examination of servicerelated antecedents to retail store performance. Journal of Organisational Behavior, 20, 943-962.

Bouckaert, L. (2015). Spirituality: The missing link in business ethics. In The spiritual dimension of business ethics and sustainability management (pp. 15-26). Cham: Springer.

Bouckaert, L., \& Zsolnai, L. (2012). Spirituality and business: An interdisciplinary overview. Society and Economy, 34(3), 489-514.

Brown, T. A., Sautter, J. A., Littvay, L., Sautter, A. C., \& Bearnes, B. (2010). Ethics and personality: Empathy and narcissism as moderators of ethical decision making in business students. Journal of Education for Business, 85(4), 203-208.

Burke, M. J., \& Dunlap, W. P. (2002). Estimating interrater agreement with the average deviation index: A user's guide. Organisational Research Methods, 5, 159-172.

Burke, M. J., Finkelstein, L. M., \& Dusig, M. S. (1999). On average deviation indices for estimating interrater agreement. Organisational Research Methods, 2, 49-68.

Carlson, D. S., \& Kacmar, K. M. (1997). Perceptions of ethics across situations: A view through three different lenses. Journal of Business Ethics, 16, 147-160.

Chuang, C., \& Liao, H. (2010). Strategic human resource management in service context: Taking care of business by taking care of employees and customers. Personnel Psychology, 63, 153-196. 
de Klerk, J. J. (2005). Spirituality, meaning in life, and work wellness: A research agenda. International Journal of Organisational Analysis, 13(1), 64-88.

DeConinck, J. B. (2010). The influence of ethical climate on marketing employees' job attitudes and behaviors. Journal of Business Research, 63(4), 384-391.

Demirtas, O., \& Akdogan, A. A. (2015). The effect of ethical leadership behavior on ethical climate, turnover intention, and affective commitment. Journal of Business Ethics, 130(1), 59-67.

Dent, E. B., Higgins, M. E., \& Wharff, D. M. (2005). Spirituality and leadership: An empirical review of definitions, distinctions, and embedded assumptions. The Leadership Quarterly, $16(5), 625-653$.

Diamantopoulos, A., \& Siguaw, J. A. (2000). Introducing LISREL. London: Sage Publications.

Domino, M. A., Wingreen, S. C., \& Blanton, J. E. (2009). Social cognitive theory: The antecedents and effects of ethical climate fit on organisational attitudes of corporate accounting professionals: A reflection of client narcissism and fraud attitude risk. Journal of Business Ethics, 1-15.

Dubinsky, A. J., \& Loken, B. (1989). Analyzing ethical decision making in marketing. Journal of Business Research, 19(2), 83-107.

Duchon, D., \& Plowman, D. (2005). Nurturing the spirit at work: Impact on work unit performance. Leadership Quarterly, 16(5), 807-833.

Einolf, C. J. (2013). Daily spiritual experiences and prosocial behavior. Social Indicators Research, 110(1), 71-87.

Elçi, M., \& Alpkan, L. (2009). The impact of perceived organisational ethical climate on work satisfaction. Journal of Business Ethics, 84(3), 297-311.

Ferrell, O. C., \& Weaver, K. M. (1978). Ethical beliefs of marketing managers. Journal of Marketing, 42(July), 69-73.

Frank, R. H. (2004). What price the moral high ground. Princeton: Princeton University Press.

Frese, M., \& Zapf, D. (1988). Methodological issues in the study of work stress: Objective vs. subjective measurement of work stress and the question of longitudinal studies. In C. L. Cooper \& R. Payne (Eds.), Causes, coping and consequences of stress at work (pp. 375-411). Chichester: Wiley.

Fry, L. W., \& Matherly, L. L. (2006a). Spiritual leadership and organisational performance. Paper Presented at the Academy of Management, Atlanta.

Furnham, A. (1995). The protestant work ethic. London: Routledge.

Furnham, A. (1996). Attitudinal correlates and demographic predictors of monetary beliefs and behaviours. Journal of Organisational Behavior, 17(4), 375-388.

Gatling, A., Kim, J., \& Milliman, J. (2016). The relationship between workplace spirituality and hospitality supervisors' work attitudes: A self-determination theory perspective. International Journal of Contemporary Hospitality Management, 28(3), 1-38.

Geigle, D. (2012). Workplace spirituality empirical research: A literature review. Business and Management Review, 2(10), 14-27.

Giacalone, R. A. (2012). The challenges we face. Journal of Management, Spirituality \& Religion, 9(4), 289-293.

Giacalone, R. A., \& Jurkiewicz, C. L. (2003). Right from wrong: The influence of spirituality on perceptions of unethical business activities. Journal of Business Ethics, 46(1), 85-97.

Goebel, S., \& Weißenberger, B. E. (2017). The relationship between informal controls, ethical work climates, and organisational performance. Journal of Business Ethics, 141(3), 505-528.

Grant, A. M. (2008a). Does intrinsic motivation fuel the prosocial fire? Motivational synergy in predicting persistence, performance, and productivity. Journal of Applied Psychology, 93, 48-58.
Grant, A. M., \& Sumanth, J. J. (2009). Mission possible? The performance of prosocially motivated employees depends on manager trustworthiness. Journal of Applied Psychology, 94(4), 927-944.

Gull, G. A., \& Doh, J. (2004). The "transmutation" of the organisation: Toward a more spiritual workplace. Journal of Management Inquiry, 13(2), 128-139.

Gunther, M. (2001). God \& business. Fortune, 144(1), 58-80.

Hair, J. F., Anderson, R. E., Tatham, R. L., \& Black, W. C. (1998). Multivariate data analysis. Englewood Cliffs: Prentice-Hall.

Hansen, S. D., Dunford, B. B., Alge, B. J., \& Jackson, C. L. (2016). Corporate social responsibility, ethical leadership, and trust propensity: A multi-experience model of perceived ethical climate. Journal of Business Ethics, 137, 649-662.

Houghton, J. D., Neck, C. P., \& Krishnakumar, S. (2016). The what, why, and how of spirituality in the workplace revisited: A 14-year update and extension. Journal of Management, Spirituality \& Religion, 13(3), 177-205.

Hu, L. T., \& Bentler, P. (1995). Evaluating model fit. In R. H. Hoyle (Ed), Structural equation modeling: Concepts, issues, and applications (pp. 76-99). London: Sage.

Huhtala, M., Tolvanen, A., Mauno, S., \& Feldt, T. (2015). The associations between ethical organisational culture, burnout, and engagement: A multilevel study. Journal of Business and Psychology, 30(2), 399-414.

Hunt, S. D., van Wood, R., \& Chonko, L. B. (1989). Corporate ethical values and organisational commitment in marketing. Journal of Marketing, 53, 79-90.

Jackson, K. T. (1999). Spirituality as a foundation for freedom and creative imagination in international business ethics. Journal of Business Ethics, 19(1), 61-70.

James, L. R., Mulaik, S. A., \& Brett, J. M. (2006). A tale of two methods. Organisational Research Methods, 9, 233-244.

Johnson, C. E. (2009). Spirituality and ethical leadership: Moral persons and moral managers. Faculty Publications - School of Business. Paper 79. Assessed via: http://digitalcommons.georgefox. $\mathrm{edu} / \mathrm{gfsb} / 79$.

Jones, T. M. (1991). Ethical decision making by individuals in organisations: An issue-contingent model. Academy of Management Review, 16(2), 366-395.

Jurkiewicz, C. L., \& Giacalone, R. A. (2004). A values framework for measuring the impact of workplace spirituality on organisational performance. Journal of Business Ethics, 49, 129-142.

Kamoche, K., \& Pinnington, A. H. (2012). Managing people 'spiritually': A Bourdieusian critique. Work, Employment and Society, 26(3), 497-513.

Karakas, F., \& Sarigollu, E. (2017). Spirals of spirituality: A qualitative study exploring dynamic patterns of spirituality in Turkish organisations. Journal of Business Ethics. 1-23.

Kenny, D. A., Kashy, D. A., \& Bolger, N. (1998). Data analysis in social psychology. In D. Gilbert, S. T. Fiske \& G. Lindzey (Eds.), Handbook of social psychology (Vol. 1, 4th edn., pp. 233-265). New York: McGraw-Hill.

Kohlberg, L. (1984). The philosophy of moral development. New York: Harper \& Row.

Kolodinsky, R. W., Giacalone, R. A., \& Jurkiewicz, C. L. (2008). Workplace values and outcomes: Exploring personal, organisational and interactive workplace spirituality. Journal of Business Ethics, 81, 465-480.

Kozlowski, S. J., \& Klein, K. L. (2000). A multilevel approach to theory and research in organisations: Contextual, temporal, and emergent processes. In K. J. Klein \& S. W. Kozlowski (Eds.), Multilevel theory, research, and methods in organisations (pp. 3-90). San Francisco: Jossey-Bass.

Lee, S., Lovelace, K. J., \& Manz, C. C. (2014). Serving with spirit: An integrative model of workplace spirituality within service 
organisations. Journal of Management, Spirituality \& Religion, $11,45-64$.

Leung, A. S. (2008). Matching ethical work climate to in-role and extra-role behaviors in a collectivist work setting. Journal of Business Ethics, 79(1), 43-55.

Liao, H., \& Chuang, A. (2004). A multilevel investigation of factors influencing employee service performance and customer outcomes. Academy of Management Journal, 47, 41-58.

MacKinnon, D. P., Lockwood, C. M., Hoffman, J. M., West, S. G., \& Sheets, V. (2002). A comparison of methods to test mediation and other intervening variables effects. Psychological Methods, 7, 83-104.

Madden, L., Mathias, B., \& Madden, T. (2015). In good company: The impact of perceived organisational support and positive relationships at work on turnover intentions. Management Research Review, 38(3), 242.

Manroop, L., Singh, P., \& Ezzedeen, S. (2014). Human resource systems and ethical climates: A resource-based perspective. Human Resource Management, 53(5), 795-816.

Martin, C. A., Rivera, D. E., Riley, W. T., Hekler, E. B., Buman, M. P., Adams, M. A., \& King, A. C. (2014). A dynamical systems model of social cognitive theory. Paper presented at the American Control Conference, Portland

Mathieu, J. E., \& Farr, J. L. (1991). Further evidence for the discriminate validity of measures of organisational commitment, job involvement, and job satisfaction. Journal of Applied Psychology, 76, 127-133.

Mayer, D. M., Nurmohamed, S., Trevino, L. K., Shapiro, D. L., \& Schminke, M. (2013). Encouraging employees to report unethical conduct internally: It takes a village. Organisational Behavior and Human Decision Processes, 121(1), 89-103.

Maynard, H. B. (1992). Evolution of human consciousness. In J. Renesch (Ed.), New traditions in business: Spirit and leadership in the 21st century (pp. 39-52). San Francisco: Berrett-Koehler.

McGhee, P., \& Grant, P. (2008). Spirituality and ethical behaviour in the workplace: Wishful thinking or authentic reality. EJBOElectronic Journal of Business Ethics and Organisation Studies, 3(2), 61-69.

McKee, D. (2003). Spirituality and marketing: An overview of the literature. In R. A. Giacalone \& C. L. Jurkiewicz (Eds.), Handbook of workplace spirituality and organisational performance (pp. 57-75). Armonk: M.E. Sharpe.

Miller, W. C. (1992). How do we put our spiritual values to work? In J. Renesch (Ed.), New traditions in business: Spirit and leadership in the 21 st century (pp. 69-80). San Francisco: Berrett-Koehler.

Milliman, J., Czaplewski, A. J., \& Ferguson, J. (2003). Workplace spirituality and employee work attitudes: An exploratory empirical assessment. Journal of Organisational Change Management, $16(4), 426-447$.

Mitroff, I. I. (2003). Do not promote religion under the guise of spirituality. Organisation, 10(2), 375-382.

Morgan, J. F. (2005). Religion at work: A legal quagmire. Managerial Law, 47(3/4), 247-259.

Mulki, J. P., Jaramillo, J. F., \& Locander, W. B. (2008). Effect of ethical climate on turnover intention: Linking attitudinal-and stress theory. Journal of Business Ethics, 78(4), 559-574.

Nielsen, T. M., Bachrach, D. G., Sundstrom, E., \& Halfhill, T. R. (2012). Utility of OCB: Organisational citizenship behavior and group performance in a resource allocation framework. Journal of Management, 38(2), 668-694.

Oakley, J., \& Cocking, D. (2001). Virtue ethics and professional roles. Cambridge: Cambridge University Press.

Organ, D. W. (1988). Organisational citizenship behaviour: The good soldier syndrome. Lexington: Lexington Books.
Parboteeah, K. P., \& Cullen, J. B. (2003). Ethical climates and spirituality. Handbook of Workplace Spirituality and Organisational Performance, 137-151.

Parboteeah, K. P., \& Kapp, E. A. (2008). Ethical climates and workplace safety behaviors: An empirical investigation. Journal of Business Ethics, 80, 515-529.

Pawar, B. (2014). Leadership spiritual behaviors toward subordinates: An empirical examination of the effects of a leader's individual spirituality and organisational spirituality. Journal of Business Ethics, 122, 439-452. 1772-5.

Pawar, B. S. (2009). Individual spirituality, workplace spirituality and work attitudes: An empirical test of direct and interaction effects. Leadership\& Organisation Development Journal, 30, 759-777.

Petchsawang, P., \& McLean, G. N. (2017). Workplace spirituality, mindfulness meditation, and work engagement. Journal of Management, Spirituality \& Religion, 14(3), 216-244.

Podsakoff, P. M., Ahearne, M., \& MacKenzie, S. B. (1997). Organisational citizenship behavior and the quantity and quality of work group performance. Journal of Applied Psychology, 82(2), 262-269.

Podsakoff, P. M., MacKenzie, S. B., Lee, J., \& Podsakoff, N. P. (2003). Common method biases in behavioral research: A critical review of the literature and recommended remedies. Journal of Applied Psychology, 88, 879-903.

Podsakoff, P. M., MacKenzie, S. B., Paine, J. B., \& Bachrach, D. G. (2000). Organisational citizenship behaviors: A critical review of the theoretical and empirical literature and suggestions for future research. Journal of Management, 26(3), 513-563.

Preacher, K. J., \& Hayes, A. F. (2008). Asymptotic and resampling strategies for assessing and comparing indirect effects in multiple mediator models. Behavior Research Methods, 40, 879-891.

Roof, R. A. (2015). The association of individual spirituality on employee engagement: The spirit at work. Journal of Business Ethics, 130(3), 585-599.

Saroglou, V., Pichon, I., Trompette, L., Verschueren, M., \& Dernelle, R. (2005). Prosocial behavior and religion: New evidence based on projective measures and peer ratings. Journal for the Scientific Study of Religion, 44(3), 323-348.

Schneider, B., Ehrhart, M. G., Mayer, D. M., Saltz, J. L., \& Niles-Jolly, K. (2005). Understanding organisation-customer links in service settings. Academy of Management Journal, 48, 1017-1032.

Schwartz, S. H., \& Bardi, A. (2001). Value hierarchies across cultures: Taking a similarities perspective. Journal of Cross-Cultural Psychology, 32(3), 268-290.

Schwepker, C. H. (1999). Understanding salespeople's intention to behave unethically: The effects of perceived competitive intensity, cognitive moral development and moral judgment. Journal of Business Ethics, 21(4), 303-316.

Schwepker, C. H. (2001). Ethical climate's relationship to job satisfaction, organisational commitment, and turnover intention in the salesforce. Journal of Business Research, 54(1), 39-52.

Schwepker, C. H., \& Hartline, M. D. (2005). Managing the ethical climate of customer-contact service employees. Journal of Service Research, 7(4), 377-397.

Sheep, M. L. (2006). Nurturing the whole person: The ethics of workplace spirituality in a society of organisations. Journal of Business Ethics, 66, 357-375.

Shin, Y. (2012). CEO ethical leadership, ethical climate, climate strength, and collective organisational citizenship behavior. Journal of Business Ethics, 108(3), 299-312.

Shin, Y., \& Choi, J. N. (2010). What makes a group of good citizens? The role of perceived group-level fit and critical psychological states in organisational teams. Journal of Occupational and Organisational Psychology, 83, 531-552.

Shinde, U., \& Fleck, E. (2015). What spirituality can bring to leaders and managers: Enabling creativity, empathy and a stress 
free workplace. Journal of Organisational Psychology, 15(1), 101-110.

Somech, A., \& Drach-Zahavy, A. (2004). Exploring organisational citizenship behaviour from an organisational perspective: The relationship between organisational learning and organisational citizenship behaviour. Journal of Occupational and Organisational Psychology, 77(3), 281-298.

Sprecher, S., \& Fehr, B. (2005). Compassionate love for close others and humanity. Journal of Social and Personal Relationships, 22(5), 629-651.

Stokes, P. (2011). Critical concepts in management and organisation studies. Palgrave Macmillan: Basingstoke.

Trevino, L. K. (1986). Ethical decision making in organisations: A person-situation interactionist model. Academy of Management Review, 11(3), 601-617.

Trevino, L. K., Butterfield, K. D., \& McCabe, D. L. (2001). The ethical context in organisations: Influences of employee attitudes and behaviors. In J. Dienhart, D. Moberg \& R. Duska (Eds.), The next phase of business ethics: Integrating psychology and ethics (pp. 301-337). Greenwich: JAI.

Valentine, S., \& Barnett, T. (2003). Ethics code awareness, perceived ethical values, and organisational commitment. Journal of Personal Selling \& Sales Management, 23(4), 359-367.

Van Scotter, J. R., \& Motowidlo, S. J. (1996). Interpersonal facilitation and job dedication as separate facets of contextual performance. Journal of Applied Psychology, 81(5), 525-531.

Vande Walle, D. (1997). Development and validation of a work domain goal orientation instrument. Educational and Psychological Measurement, 57, 995-1015.

Victor, B., \& Cullen, J. B. (1988). The organisational bases of ethical work climates. Administrative Science Quarterly, 33, 101-125.

Vitell, S. J., King, R. A., Howie, K., Toti, J.-F., Albert, L., Hidalgo, E. R., \& Yacout, O. (2016). Spirituality, moral identity, and consumer ethics. Journal of Business Ethics, 139(1), 147-160.

Wang, L. C., \& Calvano, L. (2015). Is business ethics education effective? An analysis of gender, personal ethical perspectives, and moral judgment. Journal of Business Ethics, 126, 591-602.

Wang, Y. D., \& Hsieh, H. H. (2013). Organisational ethical climate, perceived organisational support, and employee silence: A crosslevel investigation. Human Relations, 66(6), 783-802.
Weaver, G. R. (1993). Corporate codes of ethics: Purpose, process and content issues. Business and Society, 32(Spring), 44-58.

Wech, B. A., Mossholder, K. W., Steel, R. P., \& Bennett, N. (1998). Does work group cohesiveness affect individuals' performance and organisational commitment? A cross-level examination. Small Group Research, 29(4), 472-494.

Weeks, W. A., Loe, T. W., Chonko, L. B., \& Wakefield, K. (2004). The effect of perceived ethical climate on the search for sales force excellence. Journal of Personal Selling \& Sales Management, 24(3), 199-214.

Weeks, W. A., \& Nantel, J. (1992). Corporate codes of ethics and sales force behavior: A case study. Journal of Business Ethics, 11(10), 753-760.

Wimbush, J. C., \& Shepard, J. M. (1994). Toward an understanding of ethical climate: Its relationship to ethical behavior and supervisory influence. Journal of Business Ethics, 13(8), 637-647.

Wood, R. E., \& Bandura, A. (1989). Social cognitive theory of organisational management. Academy of Management Review, 14, 361-384.

Wood, R. E., Goodman, J. S., Beckmann, N., \& Cook, A. (2010). Mediation testing in management research: a review and proposals. Organisational Research Methods, 11, 270-295.

Wyld, D. C., \& Jones, C. A. (1997). The importance of context: The ethical work climate construct and models of ethical decision making-an agenda for research. Journal of Business Ethics, 16(4), 465-472.

Zhao, X.,. Lynch Jr, J. G., \& Chen, Q. (2010). Reconsidering Baron and Kenny: Myths and truths about mediation analysis. Journal of Consumer Research, 37, 197-206.

Zsolnai, L. (2011). Spirituality and ethics in management. 2nd ed., Issues in Business Ethics 19, Springer Science Business Media B.V.

Zsolnai, L. (2015). The spiritual dimension of business ethics and sustainability management. Springer.

Publisher's Note Springer Nature remains neutral with regard to jurisdictional claims in published maps and institutional affiliations. 